\title{
Assessment of Urine Proteomics in Type 1 Primary Hyperoxaluria
}

\author{
Ellen R. Brooks ${ }^{a, b}$, e Bernd Hoppe ${ }^{c, f}$ Dawn S. Milliner ${ }^{d, e}$ Eduardo Salido ${ }^{c, g}$ \\ John Rim ${ }^{b}$ Leah M. Krevitt ${ }^{b}$ Julie B. Olson ${ }^{d, e}$ Heather E. Price ${ }^{b}$ Gulsah Vural $^{b}$ \\ Craig B. Langman ${ }^{a}$, b, e \\ ${ }^{a}$ Feinberg School of Medicine, Northwestern University, Department of Pediatrics, ${ }^{b}$ Ann \& Robert H. Lurie Children's \\ Hospital of Chicago, Division of Kidney Diseases, and Stanley Manne Children's Research Institute, Chicago, III.,

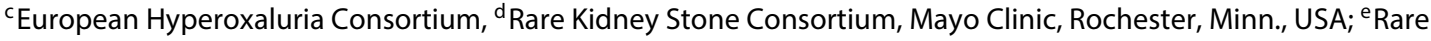 \\ Kidney Stone Consortium and ${ }^{\mathrm{f} U n i v e r s i t y ~ o f ~ B o n n, ~ C h i l d r e n ' s ~ H o s p i t a l, ~ P e d i a t r i c ~ N e p h r o l o g y, ~ B o n n, ~ G e r m a n y ; ~}{ }^{9}$ Centre \\ for Biomedical Research on Rare Diseases, University of La Laguna, Hospital Universitario de Canarias, Tenerife, Spain
}

\section{Key Words}

Primary hyperoxaluria type $1 \cdot$ Urine proteomics $\cdot$ Urine oxalate $\cdot$ Idiopathic hypercalciuria $\cdot$ Fetuin A $\cdot$ Calcium oxalate crystals · Tam Horsfall protein - Osteopontin . Epidermal growth factor

\section{Abstract \\ Background: Primary hyperoxaluria type 1 (PH1) and idio- pathic hypercalciuria $(\mathrm{IHC})$ are stone-forming diseases that may result in the formation of calcium (Ca) oxalate (Ox) stones, nephrocalcinosis, and progressive chronic kidney disease (CKD). Poorer clinical outcome in $\mathrm{PH} 1$ is segregated by the highest urine (Ur)-Ox (UrOx), while IHC outcomes are not predictable by UrCa. We hypothesized that differences would be found in selected Ur-protein (PRO) patterns in PH1 and $\mathrm{IHC}$, compared to healthy intra-familial sibling controls (C) of $\mathrm{PH} 1$ patients. We also hypothesized that the PRO pat- terns associated with higher UrOx levels would reflect injury, inflammation, biomineralization, and abnormal tissue repair processes in PH1. Methods: Twenty four-hour Ur samples were obtained from 3 cohorts: PH1 $(n=47) ; \mathrm{IHC}(n=35)$ and $C(n=13)$ and were analyzed using targeted platform-based multi-analyte profile immunoassays and for UrOx and UrCa}

by biochemical measurements. Results: Known stone matrix constituents, osteopontin, calbindin, and vitronectin were lowest in PH1 (C > IHC > PH1; $p<0.05)$. Ur-interleukin-10; chromogranin $\mathrm{A}$; epidermal growth factor (EGF); insulin-like growth factor-1 (IGF-1), and macrophage inflammatory PRO1a (MIP-1a) were higher in $\mathrm{PH} 1>\mathrm{C}(\mathrm{p}=0.03$ to $\mathrm{p}<0.05)$. Fetuin A; IGF-1, MIP-1a, and vascular cell adhesion molecule-1 were highest in $\mathrm{PH} 1>\mathrm{IHC}(\mathrm{p}<0.001$ to $\mathrm{p}=0.005)$. Conclusion: $\mathrm{PH} 1$ Ur-PROs reflected overt inflammation, chemotaxis, oxidative stress, growth factors (including EGF), and pro-angiogenic and calcification regulation/inhibition compared to the $\mathrm{C}$ and IHC cohorts. Many of the up- and downregulated $\mathrm{PH} 1-\mathrm{PRO}$ s found in this study are also found in CKD, acute kidney injury, stone formers, and/or stone matrices. Further data analyses may provide evidence for $\mathrm{PH} 1$ unique PROs or demonstrate a poorer clinical outcome.

(c) 2016 S. Karger AG, Basel

\section{Introduction}

Primary hyperoxaluria type 1 (PH1: OMIM \#259900) is a rare autosomal recessive disorder that has more than 100 identified mutations in the hepatic-specific peroxi-

\section{KARGER}

E-Mail karger@karger.com

www.karger.com/ajn
(C) 2016 S. Karger AG, Basel

0250-8095/16/0434-0293\$39.50/0
Ellen R. Brooks

Ann \& Robert H. Lurie Children's Hospital of Chicago

Division of Kidney Diseases, 225 E. Chicago Ave., \#37

Chicago, IL 60611 (USA)

E-Mail e-brooks3@northwestern.edu 
somal enzyme alanine:glyoxylate aminotransferase (AGXT) gene, which is located on chromosome $2 \mathrm{q} 37.3$ [1]. Reduced hepatic AGXT-1 (AGT1) peroxisomal enzymatic activity results in a severe, inexorable hepatic overproduction of oxalate $(\mathrm{Ox})$, high urine (Ur)-Ox (UrOx) concentrations, calcium $\mathrm{Ox}(\mathrm{CaOx})$ monohydrate (COM) nephrolithiasis, nephrocalcinosis, and chronic kidney disease (CKD) [2]. In a majority of patients, end-stage renal disease (ESRD) develops and kidney and liver transplantation is the only answer for longterm survival.

To date a modest genotype-phenotype correlation has been demonstrated in $\mathrm{PH} 1$ between patients and within families, resulting in a wide spectrum of heterogeneity of $\mathrm{PH} 1$ phenotypic disease expression. One exception may be the PH1-homozygous p.Gly170Arg AGXT mutation that is responsive to pharmacologic doses of vitamin B6 with UrOx substantially reduced or normalized, depending on whether 1 or 2 copies of the mutation exist [3]. However, for most PH1 mutations, the age of symptom onset and progression of CKD are highly variable. Thus, with incomplete insight into how rapidly the disease will manifest itself, along with a prevalence of $1: 151,887$, it is not surprising that this rare orphan disease is often not diagnosed until ESRD and systemic oxalosis develop [4, 5]. Longitudinal research reports of PH1-CKD patterns are limited since late diagnosis has historically prohibited the study of early clinical patterns of disease progression. Only in recent years have PH1 biobanks been formed to archive and study biospecimens for research on this rare disease. Two such registries with biobanks are the Rare Kidney Stone Consortium (RKSC) with its International Registry and Biobank for Hereditary Calcium Stone Diseases, at Mayo Clinic, Rochester, Minn., USA; and the European Hyperoxaluria Consortium (OXALEUROPE), a PH registry and biobank at University Children's Hospital, University of Bonn, Germany.

With these resources available, we examined 24-hour PH1-Ur proteomic patterns and compared them to patients with a history of a common stone-forming disease, idiopathic hypercalciuria (IHC). These cohorts were compared to healthy siblings of $\mathrm{PH} 1$ patients, which served as intra-familial controls (C).

We hypothesized Ur-PH1 and -IHC would exhibit similar protein (PRO) patterns typical of stone formers and posited that $\mathrm{PH} 1$ would demonstrate divergent profiles of cellular injury, immune response, inflammation, biomineralization, oxidative stress, and abnormal tissue repair associated with higher UrOx levels. Our study aims included (1) demonstrate and characterize cross- sectional differences in Ur-PRO patterns in PH1, IHC, and $\mathrm{C}$ cohorts; and (2) identify, quantitate, and correlate unique PH1 biomarkers with clinical and other laboratory data.

\section{Methods}

Human Subjects Research Approval, Enrollment, and Biobank Specimens

The study protocol and consent documents were reviewed and approved by the Ann \& Robert H. Lurie Children's Hospital of Chicago Institutional Review Board (IRB), Mayo Clinic's IRB, and ethics boards at the participating institutions in Europe. Subjects seen clinically, as well as those who contacted us were enrolled in Chicago ( $\mathrm{n}=33$ ) and the University La Laguna, Hospital Universitario de Canarias, Tenerife, Spain $(n=2)$, with specimens and data de-identified, after they gave their consent to be part of this study. Patients enrolled in Chicago also gave written permission to utilize their clinical data. Anonymized 24-hour Ur aliquots and data were obtained from: OXALEUROPE $(n=23)$ and the RKSC at Mayo Clinic $(\mathrm{n}=37)$.

\section{Study Cohorts Defined}

Three cohorts were defined for this study. PH1 patients (cohort 1), were diagnosed by molecular genetic confirmation of homozygous or compound heterozygous mutations of the AGXT gene and/or by renal or hepatic biopsy. IHC patients (cohort 2) were diagnosed by 224 -hour Ur collections with UrCa $>4 \mathrm{mg} / \mathrm{kg} / 24 \mathrm{~h}$ and/or an $\mathrm{UrCa} /$ creatinine $(\mathrm{Cr})$ ratio $>0.21 \mathrm{mg} / \mathrm{mg}$ [6], and had a history of nephrolithiasis. Controls ' $\mathrm{C}$ ' (cohort 3 ) were healthy siblings of $\mathrm{PH} 1$ patients studied.

\section{Biochemical Measurements}

Twenty four-hour Ur samples were collected by IHC and PH1 subjects and instructed to continue their medications/supplements. Following specimen preparation in Chicago, de-identified specimens were sent to Litholink Corporation (LabCorp, Chicago, Ill., USA) for biochemical measurements of Ur-Ox, -Ca, -citrate, and - $\mathrm{Cr}$ concentrations unless biochemical data were provided by the biobank or clinical site. Aliquots were stored at $-80^{\circ} \mathrm{C}$ until all Ur collections and aliquots were received.

\section{Targeted Proteomics}

Proteomic analyses of the Ur specimens were completed using a proprietary Luminex platform-based immunoassay to perform established multiplexed microsphere assays for measurement of 192 targeted PROs (Myriad Rules Based Medicine, Austin Tex., USA) as previously described [7-10]. Table 1 identifies targeted Ur PROs in this investigation that were significantly different between the cohorts and/or within the PH1 cohort, and data from the literature regarding Ur-PROs from healthy individuals, CKD, acute kidney injury (AKI), stone formers, and in calculi matrices.

\section{Calculation of eGFR}

Estimated glomerular filtration rate (eGFR) values for those less than 18 years were calculated using the Schwartz formula, while adult eGFRs ( $\geq 18$ years) were calculated using the Modification of Diet in Renal Disease study formula [11, 12]. 
Table 1. Ur proteomics found in health, injury, disease, stone formers and stone matrix

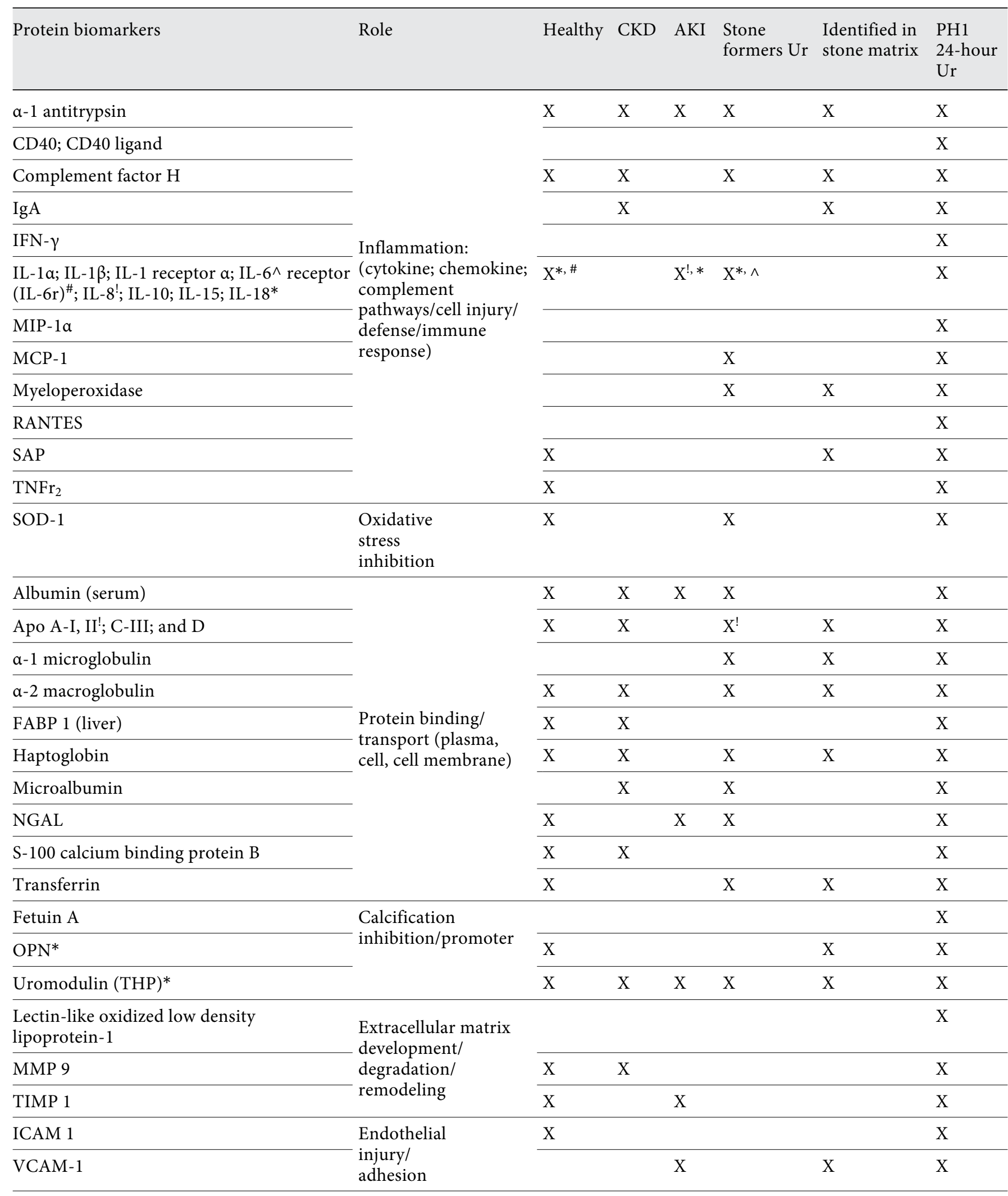


Table 1. (continued)

\begin{tabular}{|c|c|c|c|c|c|c|c|}
\hline Protein biomarkers & Role & Healthy & CKD & AKI & $\begin{array}{l}\text { Stone } \\
\text { formers Ur }\end{array}$ & $\begin{array}{l}\text { Identified in } \\
\text { stone matrix }\end{array}$ & $\begin{array}{l}\text { PH1 } \\
\text { 24-hour } \\
\text { Ur }\end{array}$ \\
\hline FGF-4 & \multirow{4}{*}{$\begin{array}{l}\text { Growth factor/cell } \\
\text { biogenesis/ } \\
\text { regeneration/ } \\
\text { fibrosis }\end{array}$} & $\mathrm{X}$ & & & & & $\mathrm{X}$ \\
\hline HGF & & & & & & & $\mathrm{X}$ \\
\hline TFF 3 & & $\mathrm{X}$ & $\mathrm{X}$ & & $\mathrm{X}$ & & $\mathrm{X}$ \\
\hline VEGF & & $\mathrm{X}$ & & & & & $\mathrm{X}$ \\
\hline $\mathrm{CgA}$ & \multirow{2}{*}{$\begin{array}{l}\text { Pro/anti-angiogenic } \\
\text { protease: protein } \\
\text { catabolism }\end{array}$} & & $\mathrm{X}$ & & & & $\mathrm{X}$ \\
\hline Cystatin C & & $\mathrm{X}$ & $\mathrm{X}$ & $\mathrm{X}$ & & & $\mathrm{X}$ \\
\hline
\end{tabular}

Ur data from random and 24-hour specimens [25-27, 29, 36, 42-45].

$\alpha=$ Alpha; $\beta$ = beta; $\gamma=$ gamma; RANTES = regulated on activation normal T cell expressed and secreted; Apo = apolipoprotein; $\mathrm{FABP}=$ fatty acid binding protein $1 ; \mathrm{NGAL}=$ neutrophil gelatinase associated lipocalin; MMP 9 = matrix metalloproteinase 9; TIMP 1 = tissue inhibitor of metalloproteinases-1; ICAM 1 = intracellular adhesion molecule 1; VCAM-1 = vascular cell adhesion molecule-1; FGF-4 = fibroblast growth factor-4; TFF 3 = trefoil factor 3; VEGF = vascular endothelial growth factor.

The following symbols represent biomarkers in row $6:^{\wedge},{ }^{*}, \#$, ! for interleukin-6 (IL-6^), IL-6 receptor (IL-6r ${ }^{\#}$ ), IL-8 , and IL-18*.

\section{Statistical Analyses}

Physiologic data were log transformed and statistical comparisons were made between the 3 cohorts using one-way analysis of variance (ANOVA) or ANOVA by Ranks for data that were not normally distributed. Student's t test or non-parametric Wilcoxon rank sum tests were used to compare between 2 cohorts. The Spearman correlation test and linear and forward stepwise regression analyses were used. All work was done using SigmaPlot $12.5^{\circledR}$ (Systat Software; ${ }^{\circledR} 2003-2013$; Chicago, Ill., USA). Gene Ontology ${ }^{\circledR}$ was used to determine relevant pathways for PH1 (GO, Gene Ontology Consortium, St. Joseph, Mich., USA).

\section{Results}

\section{Subject Characteristics}

Ninety five 24-hour Ur samples and corresponding data were studied $(\mathrm{PH} 1=47 ; \mathrm{IHC}=35 ; \mathrm{C}=13)$. Of 192 targeted PROs measured, 152 (79\%) were statistically analyzed. There were 2 reasons for excluding $21 \%$ of the markers from the statistical analyses: (1) marker levels below the detectable range and (2) some subjects had insufficient specimen volume for analyses of all markers.

Subject characteristics and their medications are in table 2. There was a significant difference in age between the 3 cohorts, with the controls being older $(\mathrm{p}<0.05)$. UrCa was greater in $\mathrm{C}$ vs. PH1 $(\mathrm{p}<0.05)$ and higher in IHC compared to PH1 ( $p<0.001)$. UrOx concentration was highest in PH1 compared to C and IHC ( $\mathrm{p}<0.05)$. Also, the IHC-eGFR was higher than that of PH1 = $155.7 \pm 49.6 ; 77.4 \pm 34.5 \mathrm{ml} / \mathrm{min} / 1.73 \mathrm{~m}^{2}(\mathrm{p}<0.001)$.

The PH1 cohort was $45 \%$ heterozygous for p.Gly170Arg and $11.4 \%$ homozygous, which is greater than expected in the $\mathrm{PH} 1$ population based on the literature but as most specimens were from biobanks, the prevalence in this study may be skewed $[3,13]$. Two of the p.Gly170Arg heterozygous patients also had the minor allele mutant Gly41Arg replacement, and might be expected to show partial response to pyridoxine [14]. AGT mutants on the minor allele Phe152Ile were expressed in 15.9\%, while $2.3 \%$ exhibited Ile244Thr, and may have been partially responsive to pyridoxine [14]. Many more patients were taking pyridoxine than those with a documented p.Gly170Arg mutation (almost $80 \%$ were on B6 (table 2) vs. 56.8\% with the p.Gly170Arg mutation with/ without minor allele mutant replacement), yet all receiving B6 were reported to be 'therapy responsive,' albeit we did not receive data on their degrees of responsiveness. Table 2 includes supplement and medication information regarding $\mathrm{K}$-phosphate, $\mathrm{K}$-citrate, $\mathrm{Mg}$, pyridoxine, hydrochlorothiazide, chlorathiodone and other therapies taken by $\mathrm{PH} 1$ and IHC cohorts $[15,16]$.

Table 3 includes 24-hour Ur-PRO cohort differences we observed with 6 PROs different between PH1 and C, and 11 PROs higher in PH1 vs. IHC. Insulin-like growth 
Table 2. Characteristics of subjects $(n=95$; mean \pm SD)

\begin{tabular}{|c|c|c|c|c|}
\hline \multirow[t]{2}{*}{ Variable } & \multicolumn{3}{|l|}{ Cohorts } & \multirow[t]{2}{*}{$p$ value } \\
\hline & $\mathrm{PH} 1(\mathrm{n}=47)$ & $\mathrm{IHC}(\mathrm{n}=35)$ & $C(n=13)$ & \\
\hline Gender, M/F & $23 / 24$ & $17 / 18$ & $6 / 7$ & - \\
\hline Age, years & $21.4 \pm 16.3^{*}$ & $12.1 \pm 5.2^{*}$ & $35.2 \pm 17.8^{*}$ & $<0.001$ \\
\hline $\mathrm{UrCa}, \mathrm{mg} / \mathrm{kg} / 24 \mathrm{~h}$ & $1.59 \pm 1.51^{*}$ & $4.23 \pm 3.78$ & $2.55 \pm 1.09^{*}$ & $<0.001$ \\
\hline $\mathrm{UrOx}, \mathrm{mmol} / \mathrm{l} / 1.73 \mathrm{~m}^{2}$ & $1.24 \pm 0.74^{*}$ & $0.53 \pm 0.45$ & $0.40 \pm 0.22$ & $<0.001$ \\
\hline Ur citrate/Cr & $1.28 \pm 3.50^{*}$ & $0.52 \pm 0.31^{*}$ & $1.34 \pm 1.23$ & $<0.05$ \\
\hline \multicolumn{5}{|l|}{ Supplements and medications, \% } \\
\hline Pyridoxine & 78.7 & 3.0 & 0.0 & \\
\hline Potassium citrate & 29.7 & 47.0 & 0.0 & \\
\hline Potassium phosphate & 38.3 & 0.0 & 0.0 & \\
\hline Sodium bicarbonate/sodium citrate & 10.6 & 3.0 & 0.0 & \\
\hline Magnesium & 6.3 & 3.0 & 0.0 & \\
\hline Phosphate (elemental) & 2.0 & 0.0 & 0.0 & \\
\hline Hydrochlorothiazide & 2.0 & 17.6 & 0.0 & \\
\hline Chlorathiodone & 0.0 & 44.0 & 0.0 & \\
\hline
\end{tabular}

Table 3. Protein biomarkers highest in $\mathrm{PH} 1$ compared to $\mathrm{C}$ and $\mathrm{IHC}$

\begin{tabular}{|c|c|c|}
\hline Biomarker & Role & $\mathrm{p}$ value \\
\hline \multicolumn{2}{|l|}{$\mathrm{PH} 1>\mathrm{C}$} & $<0.05$ \\
\hline $\begin{array}{l}\text { EGF } \\
\text { FGF-4 } \\
\text { IGF-1* }\end{array}$ & Cell biogenesis/growth and proliferation & $<0.05$ \\
\hline IL-10 & Anti-inflammatory & 0.03 \\
\hline MIP-1a* & Chemotaxis & $<0.05$ \\
\hline \multicolumn{3}{|l|}{ PH1 > IHC } \\
\hline IGF- $1^{*}$ & Cell biogenesis/growth and proliferation & $<0.001$ \\
\hline Fetuin A & Inhibition of crystallization/extraosseous calcification & 0.002 \\
\hline $\begin{array}{l}\text { IL-1 } \alpha, \text { IL- } 8, \text { IL-15 } \\
\text { MIP-1 } \alpha^{*}\end{array}$ & MIP-1a* & $<0.001$ to 0.049 \\
\hline Microalbumin & Transport/loss of GBM integrity & 0.02 \\
\hline Transferrin & $\begin{array}{l}\text { Transport/iron binding/transport/acute phase reactant/loss } \\
\text { of GBM integrity/inflammation }\end{array}$ & 0.015 \\
\hline VCAM-1 & Endothelial injury/adhesion & 0.0007 \\
\hline \multicolumn{3}{|c|}{$\begin{array}{l}a=\text { Alpha; FGF- } 4=\text { fibroblast growth factor- } 4 \text {; Apo = apolipoprotein; VCAM-1 = vascular cell adhesion } \\
\text { molecule- } 1 . \\
\quad \text { PROs increased in PH1 vs. C and IHC cohorts. }\end{array}$} \\
\hline
\end{tabular}


Fig. 1. Median IGF-1 in the Ur of control, IHC and $\mathrm{PH} 1$ cohorts. $\mathrm{PH} 1>\mathrm{C}$; $\mathrm{PH} 1>$ IHC. Data are log transformed.
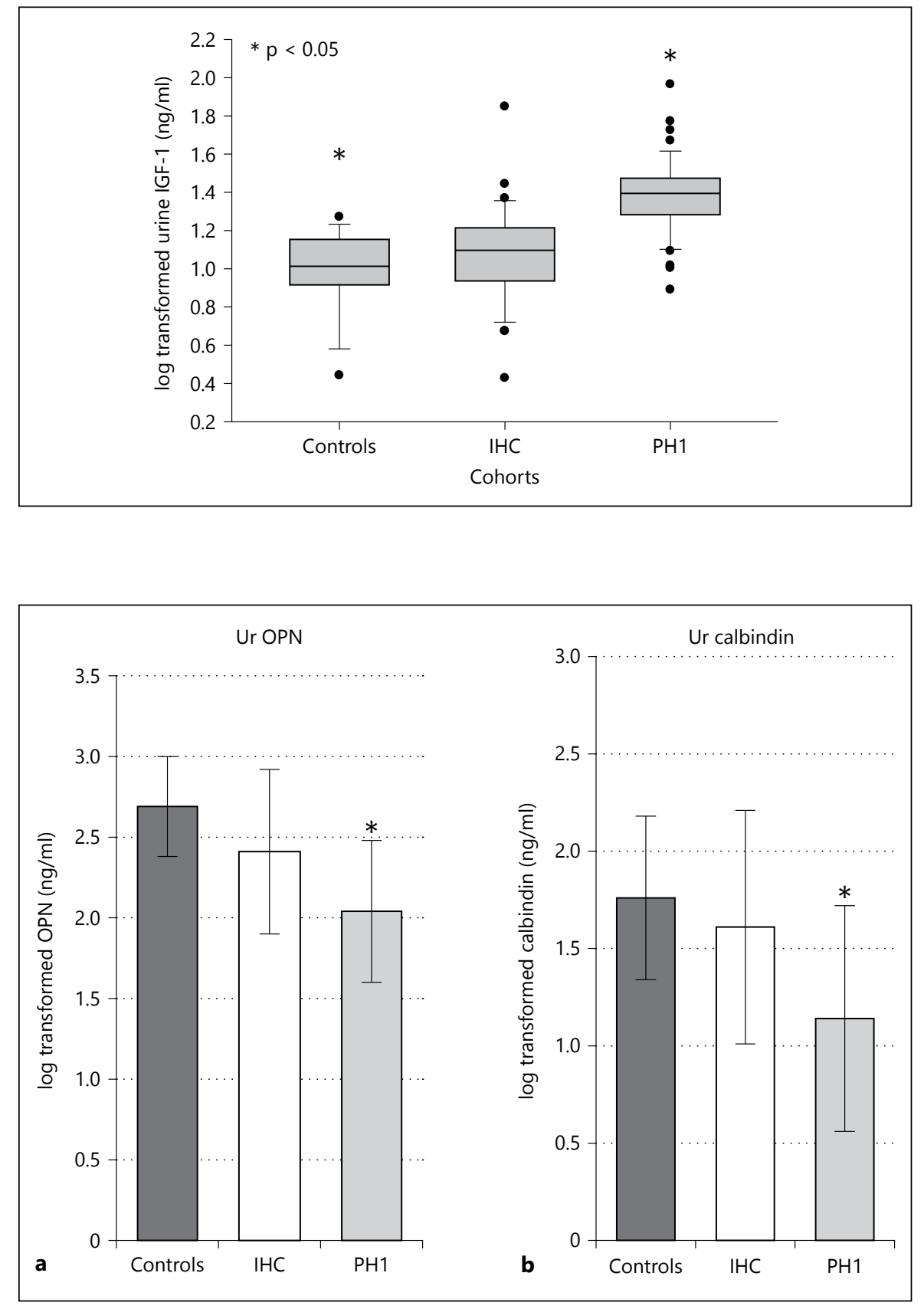

Fig. 2. a, b Known stone matrix components are lower in PH1-Ur. Data are log transformed and expressed as mean $\pm \mathrm{SD}$. a $\mathrm{OPN}\left(\mathrm{C}>\mathrm{IHC}>\mathrm{PH} 1 ;{ }^{*} \mathrm{p}<0.05\right)$; b calbindin $\left(\mathrm{C}>\mathrm{IHC}>\mathrm{PH} 1 ;{ }^{*} \mathrm{p}<0.05\right)$. factor-1 (IGF-1; fig. 1) and macrophage inflammatory PRO-1 $\alpha$ (MIP-1 $\alpha$ ) were consistently higher in PH1 vs. C $(\mathrm{p}<0.05)$ and IHC $(\mathrm{p}<0.001)$. Additionally, concentrations of osteopontin (OPN) and calbindin (known COM stone matrix components) were different between the cohorts, with $\mathrm{C}>\mathrm{IHC}>\mathrm{PH} 1$ ( $\mathrm{p}<0.05$; fig. 2). Other known stone components that were higher in $\mathrm{C}$ vs. $\mathrm{PH} 1$ were serum amyloid $\mathrm{P}$ (SAP; $\mathrm{p}=0.035)$, immunoglobulin A $(\operatorname{IgA} ; \mathrm{p}=0.048)$, and clusterin $(\mathrm{p}=0.029)$.

\section{Correlations and Regressions}

PH1 correlations demonstrated tumor necrosis factor receptor $2\left(\mathrm{TNFr}_{2}\right)$ to be associated with chromogranin $\mathrm{A}$ (CgA; $r=0.65 ; p=0.00005)$, while extracellular newly identified RAGE (receptor for advanced glycation end products)-binding PRO (ENRAGE) was correlated with interleukin-8 (IL-8); $\mathrm{r}=0.80 ; \mathrm{p}=2.0 \mathrm{E}-07)$ and myeloperoxidase $(\mathrm{r}=0.86 ; \mathrm{p}=2.0 \mathrm{E}-07)$. Superoxide dismutase-1 (SOD-1) was associated with cystatin $\mathrm{C}(\mathrm{r}=0.77$; $\mathrm{p}=$ 
2.0E-07), IL-1r $\alpha$ and IL-6r $(r=0.61 ; p=9.7 \mathrm{E}-06$ and $\mathrm{r}=$ $0.61 ; \mathrm{p}=8.6 \mathrm{E}-06$ ).

We explored relationships between $\mathrm{PH} 1$-fetuin A and PROs associated with pathologic extraosseous mineralization. Fetuin A was best predicted by: SOD-1, IL-8, MIP$1 \alpha$, and monocyte chemoattractant PRO- 1 (MCP- $1 ; \mathrm{R}^{2}=$ $0.75 ; \mathrm{p}<0.001)$ and correlated with IL-8 ( $\mathrm{p}=1.75 \mathrm{E}-08)$.

PH1-Tam Horsfall PRO (THP) was an independent predictor of OPN $\left(\mathrm{R}^{2}=0.14 ; \mathrm{p}=0.003\right)$. THP was strongly correlated with the epidermal growth factor (EGF; $r=$ $0.81 ; \mathrm{p}=2.0 \mathrm{E}-07)$.

MIP-1a was highest in PH1 and best explained by $\mathrm{CgA}$, with eGFR and cystatin $\mathrm{C}$ held constant in the model $\left(\mathrm{R}^{2}=0.93 ; \mathrm{p}=0.035\right)$. PH1-CgA was also inversely correlated with eGFR $(r=-0.35 ; \mathrm{p}=0.04)$.

\section{PH1 Data Dichotomized for 24-Hour UrOx}

We dichotomized PH1-UrOx and eGFR data by their median (Md) value, creating 2 sub-groups (table 4). The PH1-Md UrOx concentration $=1.045$ (IQR 0.256-3.046) $\mathrm{mmol} / \mathrm{l} / 1.73 \mathrm{~m}^{2}$. No significant difference was found between the UrOx sub-groups for eGFR (mean \pm SD $80.7 \pm$ $\left.30.8 ; 74.7 \pm 39.0 \mathrm{ml} / \mathrm{min} / 1.73 \mathrm{~m}^{2} ; \mathrm{p}=0.56\right)$. The Md PH1eGFR was 77.8 (IQR $8.0-164.1) \mathrm{ml} / \mathrm{min} / 1.73 \mathrm{~m}^{2}$. Similarly, no significant difference existed for 24-hour UrOx $\left(\right.$ mean \pm SD $1.35 \pm 0.82 ; 1.13 \pm 0.67 \mathrm{mmol} / \mathrm{l} / 1.73 \mathrm{~m}^{2} ; \mathrm{p}=$ 0.45 ) between the eGFR sub-groups.

OPN was lowest when UrOx was highest, while OPN and THP were observed to be lower in PH1 when eGFR was low (eGFR < Md) and higher when eGFR > Md. In contrast, $\mathrm{PH} 1$-fetuin $\mathrm{A}$, a potent calcification inhibitor, was higher than in IHC $(\mathrm{p}<0.05)$ and in the low eGFR and UrOx sub-groups, respectively. Cytokines, chemokines, and antioxidant defense were also higher when eGFR was low but was not observed when $\mathrm{UrOx}<\mathrm{Md}$. Additionally, Ur-IGF-1 was highly expressed in PH1 vs. IHC and C $(\mathrm{p}<0.05)$ and in both PH1-UrOx sub-groups. IGF-1 was also higher in the PH1 low eGFR sub-group, denoting more advanced CKD.

Using Gene Ontology ${ }^{\odot}$, p38 mitogen-activated PRO kinase (MapK) was recognized as a focal pathway element and was supported by our findings of the genes that were elevated in PH1-Ur, including cell proliferation $(\mathrm{p}=5.78 \mathrm{E}-$ $06)$; regulation of ERK1 and ERK2 cascade $(\mathrm{p}=5.23 \mathrm{E}-05)$; and stem cell development and proliferation $(\mathrm{p}=4.23 \mathrm{E}-05$ and $p=9.15 \mathrm{E}-05)$. We further noted that interferon- $\gamma$ $($ IFN- $\gamma$ ), an immunomodulator, was significantly lower in the PH1-UrOx > Md and eGFR < Md sub-groups. Also, IL-15, which is expressed in renal cells and a modulator of immune response [17], was higher in $\mathrm{PH} 1-\mathrm{UrOx}>\mathrm{Md}$.
Table 4. Proteomic marker differences by PH1 sub-group (dichotomized by Md-UrOx concentration and eGFR!); $\mathrm{p}<0.05$

\begin{tabular}{|c|c|c|c|c|}
\hline \multirow[t]{2}{*}{ Variables } & \multicolumn{2}{|l|}{ UrOx } & \multicolumn{2}{|l|}{ eGFR } \\
\hline & $\begin{array}{l}\mathrm{UrOx}< \\
\mathrm{Md}\end{array}$ & $\begin{array}{l}\mathrm{UrOx}> \\
\mathrm{Md}\end{array}$ & $\begin{array}{l}\text { eGFR < } \\
\mathrm{Md}\end{array}$ & $\begin{array}{l}\text { eGFR > } \\
\mathrm{Md}\end{array}$ \\
\hline OPN & $\uparrow$ & $\downarrow$ & $\downarrow$ & $\uparrow$ \\
\hline
\end{tabular}

HGF

ICAM-1

IFN- $\gamma$

IL-6r

$\uparrow \quad \downarrow$

$(-)$

$(-)$

LOX-1

RANTES

\begin{tabular}{lllll}
\hline EGF & & & & $\uparrow$ \\
Uromodulin (THP) & $(-)$ & $(-)$ & $\downarrow$ & \\
\hline CD40 & & & & \\
CD40L & & & \\
IL-1ra & & & $\uparrow$ & $\downarrow$ \\
NGAL & $\uparrow$ & $\downarrow$ & & \\
SOD-1 & & & & \\
TFF-3 & & & $(-)$ & $(-)$ \\
TNFr 2 & & & $\uparrow$ & $\downarrow$ \\
VCAM-1 & & $\uparrow$ & & \\
VEGF & $\downarrow$ & $\uparrow$ & & \\
\hline IL-15 & & & & \\
\hline IGF-1 & $(-)$ & $(-)$ & $\uparrow$ & $\downarrow$ \\
\hline Angiotensinogen & & & & \\
Fetuin A & & & \\
IL-1 $\beta$, IL-8 & & & & \\
\hline
\end{tabular}

' Md-PH1 UrOx = $1.045($ IQR $0.256-3.046) \mathrm{mmol} / \mathrm{l} / 1.73 \mathrm{~m}^{2} /$ $24 \mathrm{~h}$; Md-PH1-eGFR = $77.8($ IQR $8.0-164.1) \mathrm{ml} / \mathrm{min} / 1.73 \mathrm{~m}^{2}$.

$\alpha=$ Alpha; $\beta=$ beta; $\gamma=$ gamma; ICAM- 1 = intracellular adhesion molecule-1; LOX-1 = lectin-like oxidized LDL receptor 1; RANTES $=$ regulated on activation normal $\mathrm{T}$ cell expressed and secreted; CD40 = cluster of differentiation -40 antigen; $\mathrm{CD} 40 \mathrm{~L}=$ CD40 ligand; NGAL = neutrophil gelantinase-associated lipocalin; TFF-3 = trefoil factor-3; VCAM-1 = vascular cell adhesion molecule-1; VEGF = vascular endothelial growth factor.

\section{Discussion}

Renal injury and cell death in $\mathrm{PH} 1$ are directly related to Ox exposure, its poor solubility and tendency for renal tubular crystallization. Consistent with this, AGXT knock out -/- (KO) mice demonstrate cell injury and death linked to plasma $\mathrm{Ox}$ in a dose-dependent manner, and OPN and THP exhibit an affinity for intra-tubular epithelial binding to $\mathrm{CaOx}$ crystals in the UF [18]. Moreover, when OPN and THP are not expressed in double KO 
mice with experimentally induced hyperoxaluria, extensive crystal and stone formation occur. Thus, OPN and THP play important roles for the inhibition of extraosseous calcification in renal tubular epithelial cells [18].

$\mathrm{K}$ citrate and $\mathrm{K}$ Phos treatments are used to reduce or eliminate $\mathrm{CaOx}$ crystals, stone formation and resulting tubular nephrotoxicity. While almost half of the IHC cohort was taking $\mathrm{K}$-citrate, the mean $\pm \mathrm{SD}$ of $\mathrm{IHC}-\mathrm{UrCa}=$ $4.23 \pm 3.78$, which is 'persistent IHC' [15]. Conversely, $38.3 \%$ of $\mathrm{PH} 1$ were taking $\mathrm{K}$ Phos with fewer on K citrate, yet had the highest UrOx and lowest UrCa levels, the latter most likely from $\mathrm{Ca}$ retention for stone formation and nephrocalcinosis.

The mechanisms of Ox-associated nephrotoxicity exhibited by $\mathrm{PH} 1$ proteomics encompasses p38 MAPK pathway upregulation, phosphorylation, and activation of transcription factors that are critical for eliciting inflammation, oxidative stress, PT cell injury, necrosis and apoptosis. However, this pathway does not appear to be unique to $\mathrm{PH} 1$, as similar PROs are found in CKD, AKI and stone formers [19-23].

Clearly, many of the PH1 markers we found to be upor downregulated are important mediators (or receptors) of pro-inflammatory cytokines, adaptive immune responses, and compensatory responses to inhibit inflammation. Five such examples include MIP-1 $\alpha$, IL-8, IL-15, IL-10, and $\mathrm{TNFr}_{2}$; a chemokine; neutrophil chemotactic factor; pro-inflammatory cytokine that upregulates macrophages; other inflammatory cytokines and immune responses; and a cytokine receptor, respectively, that are directly associated with NF- $\kappa \mathrm{B}$ pathway upregulation. Other upregulated $\mathrm{PH} 1$ biomarkers were vascular cell adhesion molecule- 1 , IL- $1 \beta$, TNF- $\alpha$, MCP- 1 , and IFN- $\gamma$, which are associated with inflammatory cell migration as is IHC-MCP-1 [15]. Higher PT injury marker levels were observed when PH1-eGFR < Md: neutrophil gelantinaseassociated lipocalin, trefoil factor-3, and SOD-1.

Our Gene Ontology results were consistent with inflammation in $\mathrm{PH} 1$ occurring due to NF- $\mathrm{\kappa B}$ pathway upregulation, providing important credence to our conclusions. Expression of some PH1 biomarkers that reflect MAPK pathway activation also change in CKD and AKI [24-29]. In cell culture, this pathway is upregulated due to $\mathrm{CaOx}$ crystal deposition within the renal tubular epithelium creating crystal-induced disruption of DT epithelial cell tight junctions and loss of tubular paracellular barrier integrity [30]. These findings soundly emphasize the consequences of chronic tubular over exposure to $\mathrm{CaOx}$ crystals and the mechanisms by which $\mathrm{PH} 1-\mathrm{CKD}$ progresses over time and tubular injury is demonstrated in $\mathrm{CaOx}$ stone disease(IHC).
PH1-MIP-1 $\alpha$, which was higher vs. IHC and C may serve as a renal injury marker associated with $\mathrm{CaOx}$ crystal-related nephrotoxicity. CgA was also an independent predictor of MIP-1 $1 \alpha$, correlated with $\mathrm{TNFr}_{2}$, and increases in adults with impaired renal function and ESRD [24, 31]. Thus, CgA may play a role in renal fibrosis development via endothelin-1 in PH1-CKD progression since the renal tubulointerstitium contains dendritic cells and envelop the nephron [32].

Our results also confirmed upregulation of a number of growth factors in PH1-CKD. Results from a large international study of 3 independent adult CKD cohorts identified Ur-EGF/Cr as a significant predictor of interstitial fibrosis, tubular atrophy, eGFR, and CKD progression. A one unit increase in Ur-EGF/Cr $(\log )$ was associated with a hazard ratio for $\mathrm{CKD}$ progression $=3.73$ (1.85-7.69)-fold increased risk [26]. Our findings of upregulated Ur-EGF may constitute relevant and promising data. Other work in adults with more advanced CKD than seen in our study subjects demonstrates some overlap with our Ur-PRO findings, including lower THP and higher apolipoprotein A-1 and $\alpha-1$ antitrypsin associated with rapid kidney function decline [22]. Perhaps PH1 leads to more rapid changes in PRO regulation despite having a higher eGFR.

Another growth factor, IGF-1, which is highly expressed in the kidneys was consistently higher in $\mathrm{PH} 1$ vs. IHC, and when $\mathrm{UrOx}>\mathrm{Md}$. It has been positively associated with CKD in adult gender- and multivariate-adjusted models [25]. Thus, IGF-1 upregulation in PH1-CKD is plausible and may provide a protective role of cell proliferation, differentiation, growth, and repair when $\mathrm{Ox}$ crystal related renal tubular injury occurs [33].

Alternatively, hepatocyte growth factor (HGF), which has anti-inflammatory properties was increased when $\mathrm{PH} 1-\mathrm{UrOx}<\mathrm{Md}$ but reduced when UrOx was highest, possibly reflecting a protective response. HGF suppresses macrophage infiltration and abrogates chemokine expression via disruption of NF- $\kappa B$ in human kidney epithelial cell culture and downregulates TGF- $\beta$-induced renal fibrosis in nephrotic mice $[34,35]$. However, it is possible that protective responses by HGF may be downregulated (lost) when $\mathrm{PH} 1-\mathrm{UrOx}$ is highest.

Using Gene Ontology, IGF-1 theoretically serves as an upregulator of the NF- $\mathrm{kB}$ pathway and fetuin A upregulation $(p=0.04)$. Fetuin A was higher when eGFR was low, suggesting it may inhibit pathologic biomineralization in the PT when GFR is low. It is a potent calcification inhibitor and was higher in PH1 > IHC. However, we could not establish whether PH1-Ur-fetuin A, -Ur-Ox or -Ur-Ca 
were different in the presence or absence of nephrolithiasis/urolithiasis ( $94 \%$ had a positive history of calculi) or nephrocalcinosis (15\% had documented nephrocalcinosis) because the sub-groups were small and unequally divided, with insufficient power to make any determinations.

$\mathrm{PH} 1$ also exhibited lower concentrations of PROs that are known to be found within the organic matrix of COM calculi (OPN and calbindin) [36]. SAP, IgA and clusterin were downregulated in Ur-PH1 < C. Similarly, OPN and THP were lower when PH1-eGFR $<$ Md, which may also reflect calculi organic matrix macromolecule retention. OPN is upregulated in renal tubules following ethylene glycol and vitamin $\mathrm{D}_{3}$ administration in THP-/- (KO) mice with development of $\mathrm{CaOx}$ crystals, while THP [37] directly correlates with CKD-eGFR [27]. We similarly demonstrated THP to be lower when PH1-eGFR $<$ Md and conversely THP was higher when eGFR $>\mathrm{Md}$. Thus, it is plausible that OPN and THP may exhibit a diminished ability to inhibit extraosseous mineralization or are downregulated as GFR declines and UrOx rises.

The PH1 Ur-PROs we found to be upregulated suggest that chemotaxis, oxidative stress, inflammation, cell growth and proliferation, are reflective of compensatory responses to control tubular injury associated with chronic $\mathrm{CaOx}$ crystal exposure. We also found evidence suggesting PH1-CKD glomerular injury, including upregulated transferrin and microalbumin [28]. Although, we found some similar Ur-PRO patterns in $\mathrm{PH} 1$ and $\mathrm{IHC}$ for PROs known to be incorporated into COM stone organic matrix, we also observed divergent profiles between IHC and PH1 that we had hypothesized. Hence, an increased presence of Ur-PROs indicative of toxic injury and cell death added relevant data regarding patterns of compensatory and protective mechanisms that are driven by co-existing high UrOx and declining eGFR as PH1$\mathrm{CKD}$ progresses. Consistent with our results, our RKSC colleagues recently published data regarding higher $\mathrm{UrOx}$ being linked with a rapid GFR decline [38].

\section{Study Limitations}

Our work discussed here was limited to cross-sectional 24-hour Ur specimens. In a separate study, we are currently examining relationships between cross-sectional and prospective $\mathrm{PH} 1 \mathrm{Ur}-\mathrm{PROs}$, which will permit a more rigorous examination of longitudinal changes in inflammatory and protective tissue responses over the course of $\mathrm{PH} 1$ $\mathrm{CKD}$ progression. A majority of the $\mathrm{PH} 1$ patients who provided anonymized Ur samples for this study $(78.7 \%)$ were taking daily pyridoxine and noted to be 'responsive to therapy,' such that UrOx levels had declined with clinical treat- ment. However, the mean UrOx concentration $=1.24 \pm 74$ $\mathrm{mmol} / \mathrm{l} / 1.73 \mathrm{~m}^{2}$, which was more than 3 times higher than that of controls, even with B6 treatment. As this was a crosssectional investigation, we do not have data on prospective treatment effects on PH1-Ur proteomic patterns. We can only suggest that higher $\mathrm{UrOx}$ is associated with a more robust inflammatory proteomic response and likely contributes to $\mathrm{PH} 1-\mathrm{CKD}$ progression, which might stabilize with $\mathrm{UrOx}$ reduction from $\mathrm{B} 6$ therapy.

We are aware that the age difference of the control subjects ( $35.2 \pm 17.8$ years) vs. PH1 (21.4 \pm 16.3 years) and IHC (12.1 \pm 5.2 years) may present some confounding of our results. It is possible that the older control subjects may have had other age-related sub-clinical conditions resulting in low-grade inflammation, modest immune system disturbances, or moderate age-related decline in GFR [39]. However, we did not observe a skewed proteome profile in the cohort when compared to $\mathrm{PH} 1$ or IHC. The controls were known to be otherwise healthy and were screened to eliminate individuals taking prescription medicine or over-the-counter medications on a regular basis, since their medical records were released for our review.

One other consideration is that although we statistically examined whether eGFR differences existed for PH1 patients with high vs. low UrOx levels and found no differences, in reality, higher circulating levels of $\mathrm{Ox}$ are found in the plasma (oxalosis), with systemic $\mathrm{CaOx}$ crystal deposition when GFR is low. Conversely, it is possible that we may have found differences if we had included a control cohort with reduced eGFR that was not associated with $\mathrm{PH} 1$ or other stone diseases.

Our study methodology utilized targeted proteomic platform-based immunoassays. Therefore, other biomarkers that play a critical role in PH1-CKD may not have been identified and could have provided pertinent data on pathophysiologic mechanisms in PH1 not described here.

The strength of this study is centered on examination of 3 distinct cohorts, with 2 of them representing $\mathrm{CaOx}$ stoneforming diseases. The third cohort, controls, was comprised of first-degree relatives of $\mathrm{PH} 1$ patients. Comparison of healthy controls against stone-forming groups supported our identification of up- and downregulation of $\mathrm{Ur}$ biomarkers and possible pathologic mechanisms involved in $\mathrm{CaOx}$ crystal-related nephrotoxicity, calculi formation, and renal tissue injury and repair. In PH1, the renal tubules are reactive to much larger concentrations of $\mathrm{Ox}$ and $\mathrm{CaOx}$ crystals compared to other 'traditional' stone formers and exact an overwhelming inflammatory response leading to 
downregulation of cell repair [20,30,40,41]. Our findings clearly demonstrate a picture of inflammatory and oxidative upregulation, and growth factors-associated cell proliferation in PH1-Ur. Our future investigative findings from prospective study of $\mathrm{PH} 1$ will likely add further credence to understanding $\mathrm{PH} 1-\mathrm{CKD}$ disease progression and perhaps also identify targets for treatment.

\section{Acknowledgments}

We thank the patients and their family members who made this study possible.

\section{Support and Financial Declaration}

This work was supported by the National Institutes of Health grant \#1R44DK084634-01 and co-supported with de-identified specimens and data by the Rare Kidney Stone Consortium (RKSC) and the European Hyperoxaluria Consortium (OXALEUROPE). The RKSC, Mayo Clinic, Rochester, Minn., USA (U54DK083908) is a member of the Rare Diseases Clinical Research Network $(R D C R N)$, an initiative of the Office of Rare Diseases Research (ORDR) and NCATS. This consortium is funded through collaboration between NCATS and the NIDDK.

The authors have no personal or financial conflict of interests regarding any organizations or individuals that could be perceived as influencing this research, its design, implementation, or results published.

\section{References}

1 Danpure CJ, Rumsby G: Molecular aetiology of primary hyperoxaluria and its implications for clinical management. Expert Rev Mol Med 2004;6:1-16.

2 Coulter-Mackie MB, Lian Q, Applegarth $\mathrm{D}$, Toone J: The major allele of the alanine:glyoxylate aminotransferase gene: nine novel mutations and polymorphisms associated with primary hyperoxaluria type 1. Mol Genet Metab 2005;86:172-178.

3 Harambat J, Fargue S, Acquaviva C, Gagnadoux MF, Janssen F, Liutkus A, et al: Genotype-phenotype correlation in primary hyperoxaluria type 1: the p.Gly170arg AGXT mutation is associated with a better outcome. Kidney Int 2010;77:443-449.

4 Hopp K, Cogal AG, Bergstralh EJ, Seide BM, Olson JB, Meek AM, et al; Rare Kidney Stone Consortium: Phenotype-genotype correlations and estimated carrier frequencies of primary hyperoxaluria. J Am Soc Nephrol 2015; 26:2559-2570.

5 Hoppe B, Langman CB: A United States survey on diagnosis, treatment, and outcome of primary hyperoxaluria. Pediatr Nephrol 2003; 18:986-991.

6 Vasudevan A, Phadke KD: Fluids, electrolytes, and acid-base disorders; in Phadke KD, Goodyer P, Bitzan M (eds): Manual of Pediatric Nephrology. New York, Springer, 2014, pp 65-139.

7 Looker HC, Colombo M, Hess S, Brosnan MJ, Farran B, Dalton RN, et al; SUMMIT Investigators: Biomarkers of rapid chronic kidney disease progression in type 2 diabetes. Kidney Int 2015;88:888-896.

8 Levitsky J, Baker TB, Jie C, Ahya S, Levin M, Friedewald J, et al: Plasma protein biomarkers enhance the clinical prediction of kidney injury recovery in patients undergoing liver transplantation. Hepatology 2014;60:20172026.

9 Levitsky J, Salomon DR, Abecassis M, Langfelder P, Horvath S, Friedewald J, et al: Clini- cal and plasma proteomic markers correlating with chronic kidney disease after liver transplantation. Am J Transplant 2011;11:19721978.

10 Eisinger D, McDade R, Joos T: Quantitative multiplexed patterning of immune-related biomarkers; in Bleavins MR, Carini C, Jurima-Romet M, Rahbari R (eds): Biomarkers in Drug Development: A Handbook of Practice, Application and Strategy. Pharmaceutical Sciences Encyclopedia. Hoboken, John Wiley \& Sons, Inc., 2010, vol 70, pp 121-134.

11 Schwartz GJ, Muñoz A, Schneider MF, Mak RH, Kaskel F, Warady BA, et al: New equations to estimate GFR in children with CKD. J Am Soc Nephrol 2009;20:629-637.

12 Levey AS, Bosch JP, Lewis JB, Greene T, Rogers N, Roth D: A more accurate method to estimate glomerular filtration rate from serum creatinine: a new prediction equation. Modification of Diet in Renal Disease Study Group. Ann Intern Med 1999;130:461-470.

13 Lorenz EC, Lieske JC, Seide BM, Meek AM, Olson JB, Bergstralh EJ, et al: Sustained pyridoxine response in primary hyperoxaluria type 1 recipients of kidney alone transplant. Am J Transplant 2014;14:1433-1438.

14 Fargue S, Rumsby G, Danpure CJ: Multiple mechanisms of action of pyridoxine in primary hyperoxaluria type 1 . Biochim Biophys Acta $2013 ; 1832: 1776-1783$.

15 Santos AC, Lima EM, Penido MG, Silveira KD, Teixeira MM, Oliveira EA, et al: Plasma and urinary levels of cytokines in patients with idiopathic hypercalciuria. Pediatr Nephrol 2012;27:941-948.

16 Li X, Zhao M, Li M, Jia L, Gao Y: Effects of three commonly-used diuretics on the urinary proteome. Genomics Proteomics Bioinformatics 2014:12:120-126.

17 Eini H, Tejman-Yarden N, Lewis EC, Chaimovitz C, Zlotnik M, Douvdevani A: Association between renal injury and reduced interleukin-15 and interleukin-15 receptor levels in acute kidney injury. J Interferon Cytokine Res 2010;30:1-8.

18 Mo L, Liaw L, Evan AP, Sommer AJ, Lieske JC, Wu XR: Renal calcinosis and stone formation in mice lacking osteopontin, TammHorsfall protein, or both. Am J Physiol Renal Physiol 2007;293:F1935-F1943.

19 Merchant ML, Cummins TD, Wilkey DW, Salyer SA, Powell DW, Klein JB, et al: Proteomic analysis of renal calculi indicates an important role for inflammatory processes in calcium stone formation. Am J Physiol Renal Physiol 2008;295:F1254-F1258.

20 Mulay SR, Kulkarni OP, Rupanagudi KV, Migliorini A, Darisipudi MN, Vilaysane A, et al: Calcium oxalate crystals induce renal inflammation by NLRP3-mediated IL- $1 \beta$ secretion. J Clin Invest 2013;123:236-246.

21 Koul S, Khandrika L, Pshak TJ, Iguchi N, Pal $\mathrm{M}$, Steffan JJ, et al: Oxalate upregulates expression of IL-2R $\beta$ and activates IL-2R signaling in HK-2 cells, a line of human renal epithelial cells. Am J Physiol Renal Physiol 2014; 306:F1039-F1046.

22 Øvrehus MA, Zürbig P, Vikse BE, Hallan SI Urinary proteomics in chronic kidney disease: diagnosis and risk of progression beyond albuminuria. Clin Proteomics 2015;12: 21.

23 Boonla C, Tosukhowong P, Spittau B, Schlosser A, Pimratana C, Krieglstein K: Inflammatory and fibrotic proteins proteomically identified as key protein constituents in urine and stone matrix of patients with kidney calculi. Clin Chim Acta 2014;429:81-89.

24 Tramonti G, Ferdeghini M, Annichiarico C, Norpoth M, Donadio C, Bianchi R, et al: Relationship between renal function and blood level of chromogranin A. Ren Fail 2001;23: 449-457.

25 Teppala S, Shankar A, Sabanayagam C: Association between IGF-1 and chronic kidney disease among US adults. Clin Exp Nephrol 2010;14:440-444. 
26 Ju W, Nair V, Smith S, Zhu L, Shedden K, Song PX, et al; ERCB, C-PROBE, NEPTUNE, and PKU-IgAN Consortium: Tissue transcriptome-driven identification of epidermal growth factor as a chronic kidney disease biomarker. Sci Transl Med 2015;7:316ra193.

27 Prajczer S, Heidenreich U, Pfaller W, Kotanko P, Lhotta K, Jennings P: Evidence for a role of uromodulin in chronic kidney disease progression. Nephrol Dial Transplant 2010; 25:1896-1903.

28 Maeda H, Sogawa K, Sakaguchi K, Abe S, Sagizaka W, Mochizuki S, et al: Urinary albumin and transferrin as early diagnostic markers of chronic kidney disease. J Vet Med Sci 2015;77: 937-943.

29 Suhail SM, Woo KT, Tan HK, Wong KS: Sodium dodecyl sulfate polyacrylamide gel electrophoresis (SDS-PAGE) of urinary protein in acute kidney injury. Saudi J Kidney Dis Transpl 2011;22:739-745.

30 Peerapen P, Thongboonkerd V: p38 MAPK mediates calcium oxalate crystal-induced tight junction disruption in distal renal tubular epithelial cells. Sci Rep 2013;3:1041.

31 Castoldi G, Antolini L, Bombardi C, Perego L, Mariani $\mathrm{P}$, Viganò $\mathrm{MR}$, et al: Oxidative stress biomarkers and chromogranin $\mathrm{A}$ in uremic patients: effects of dialytic treatment. Clin Biochem 2010;43:1387-1392.

32 Soos TJ, Sims TN, Barisoni L, Lin K, Littman DR, Dustin ML, et al: CX3CR1+ interstitial dendritic cells form a contiguous network throughout the entire kidney. Kidney Int 2006; 70:591-596.
33 Feld SM, Hirschberg R, Artishevsky A, Nast C, Adler SG: Insulin-like growth factor I induces mesangial proliferation and increases mRNA and secretion of collagen. Kidney Int 1995;48:45-51.

34 Giannopoulou M, Dai C, Tan X, Wen X, Michalopoulos GK, Liu Y: Hepatocyte growth factor exerts its anti-inflammatory action by disrupting nuclear factor-kappaB signaling. Am J Pathol 2008;173:30-41.

35 Mizuno S, Matsumoto K, Nakamura T: Hepatocyte growth factor suppresses interstitial fibrosis in a mouse model of obstructive nephropathy. Kidney Int 2001;59:1304-1314.

36 Canales BK, Anderson L, Higgins L, Slaton J, Roberts KP, Liu N, et al: Second prize: comprehensive proteomic analysis of human calcium oxalate monohydrate kidney stone matrix. J Endourol 2008;22:1161-1167.

37 Mo L, Huang HY, Zhu XH, Shapiro E, Hasty DL, Wu XR: Tamm-Horsfall protein is a critical renal defense factor protecting against calcium oxalate crystal formation. Kidney Int 2004;66:1159-1166.

38 Zhao F, Bergstralh E, Mehta RA, Vaughan LE, Olson JB, Seide BM, et al; Investigators of the Rare Kidney Stone Consortium: Predictors of incident ESRD among patients with primary hyperoxaluria presenting prior to kidney failure. Clin J Am Soc Nephrol 2016; 11:119-126.
39 Bakun M, Senatorski G, Rubel T, Lukasik A, Zielenkiewicz P, Dadlez M, et al: Urine proteomes of healthy aging humans reveal extracellular matrix (ECM) alterations and immune system dysfunction. Age (Dordr) 2014; 36:299-311.

40 Schepers MS, van Ballegooijen ES, Bangma $\mathrm{CH}$, Verkoelen CF: Crystals cause acute necrotic cell death in renal proximal tubule cells, but not in collecting tubule cells. Kidney Int 2005;68:1543-1553.

41 Han HJ, Lim MJ, Lee YJ: Oxalate inhibits renal proximal tubule cell proliferation via oxidative stress, p38 MAPK/JNK, and cPLA2 signaling pathways. Am J Physiol Cell Physiol 2004;287:C1058-C1066.

42 Zhang Y, Zhang Y, Adachi J, Olsen JV, Shi R, de Souza G, et al: MAPU: Max-Planck unified database of organellar, cellular, tissue and body fluid proteomes. Nucleic Acids Res 2007;35(database issue):D771-D779.

43 Wright CA, Howles S, Trudgiant DC, Kessler BM, Reynards JM, Noble JG, et al: Label-free quantitative proteomics reveals differentially regulated proteins influencing urolithiasis. Mol Cell Proteomics 2011;10: M110.

44 Kovacevic L, Lu H, Caruso JA, Lakshmanan Y: Renal tubular dysfunction in pediatric urolithiasis: proteomic evidence. Urology 2016; pii:S0090-4295(16)00124-2.

45 Santucci L, Candiano G, Petretto A, Bruschi M, Lavarello C, Inglese E, et al: From hundreds to thousands: widening the normal human urinome. Data Brief 2014;1:25-28. 